http://www.tandfonline.com/doi/full/10.1080/13563475.2015.1034253\#

\title{
Researching local development cultures: using the qualitative interview as an interpretive lens
}

\author{
Dr. Susan Moore \\ Lecturer in Urban Development and Planning \\ Bartlett School of Planning, University College London
}

Contact details:

Bartlett School of Planning

Central House

14 Upper Woburn Place, London, WC1H 0NN

Phone: 02031089526

Email: susan.moore@ucl.ac.uk 


\title{
Researching local development cultures: using the
}

\section{qualitative interview as an interpretive lens}

\begin{abstract}
This paper directs critical reflection on the use and treatment of qualitative interviews in researching building and development actors, processes and outcomes. Using the case study of New Urbanism in Toronto, it argues that norms of self-presentation and impression management consciously or unconsciously enacted by development professionals (developers, builders, designers, planners) within the research interview constitute key data that is often overlooked in planning and urban developmentrelated research. More often than not such study is geared towards typifying development processes, identifying and prescribing industry 'best practices' and evaluating the relative success of outcomes on the ground. It is argued here that a finer-grained coding of interviews with key project-based actors directs attention to the hybrid and contingent nature of social roles in development networks and processes. This challenges researchers to examine more rigorously the identities, strategies, constraints and rationalities of development professionals to gain a deeper understanding of their agency in the (re)production of urban form and the definition of local development cultures.
\end{abstract}

Key Words: qualitative interviews, impression management, built environment, development cultures, New Urbanism, Toronto Word Count: 6900 (excluding title page, references, endnotes, table) 


\section{Introduction}

Interviewing is perhaps the most common method employed in researching built environment practices and actors (Amaratunga et al, 2002; Haigh, 2008). This is largely because it enables in-depth probing of the occupancy or socio-biographies of particular social 'roles' or types of building actor (Orum et al, 1991), as well as a fine-grained investigation of the real and perceived relations which exist between context, process and the production of built form. A few dedicated built environment methods texts (e.g. Knight and Ruddock, 2008) exist, but evidence of an academic review of methodological implications for research and policy-formulation focused on, or intersecting with, built environment practitioners and their overlapping fields ${ }^{1}$ (Bourdieu 2005) of practice, is relatively scant.

Drawing on experiences of researching private sector development actors involved in the production of four new residential developments in Toronto, Canada this paper focuses on the qualitative interview. It considers the value of the interview as an interpretive site for context-specific norms and self-presentational strategies, which can help identify characteristics of local building and development cultures, and provide insights into how to research them.

The interview is a unique encounter for which no methods text or prompt sheet can ever fully prepare a researcher. By virtue of agreeing to participate in a largely unpredictable meeting, both researcher and interviewee knowingly relinquish some degree of self-interest through their interaction (Goffman, 1959, p. 236). Likewise, 
each participant in the interview engages in strategies of managing the impression he/she is making. For example, McDowell (1998) recounted her strategy of selfpresentation in interviewing city bank employees as that of oscillating between two personas - the 'whiz kid' and the 'naïve laywoman' (p. 2138); the 'expert or ignoramus?' (p. 2137). Interviewing thus involves a series of intersections between personal biographies and substantive matters (Gubrium and Holstein, 2003, p.33).

The intent of this paper is therefore to highlight some of these intersections of content and biography and unpack their methodological and conceptual significance to the expanding field of research and theory in the built environment, not the least of which to reiterate "how deeply the power relations that emerge in interviews are embedded in the data they produce' (Briggs, 2003, p. 244). In other words, this paper argues that self-presentation and impression management in the interview are not only a methodological challenge, but are themselves key data, which often get overlooked in research geared to typifying development processes, identifying industry 'best practices' and evaluating the relative 'success' of outcomes on the ground. The tendency in planning research is to look for the predictive/prescriptive theories and the universals (Flyvberg 2006), the interview on the other hand generates contextdependent and case-specific knowledge that can support improved explorative generalization (where valuable) about a weakly understood development industry.

Implicitly, this paper supports Guy and Henneberry's (2002b) assertion that built environment studies should better understand the identities, roles and strategies of 
development professionals in order to gain a more holistic understanding of their agency. It attempts to counter the tendency in academic planning literature to conceptualise development actors as homogenous groups of public or private actors conforming to role-defined strategies and behaviours pursuant to a typified development process. This, as Henneberry and Parris (2013) admonish, elicits an under-socialised treatment of the development industry. The result is an overemphasis on structures rather than the processes of socio-spatial interaction and networking that constitute a local market. Explicitly, this paper offers a methodological intervention by unpacking the utility of acknowledging and analysing the self-presentational strategies or impression management tactics (Leary, 1996) used by development professionals within research interviews. The emphasis is herein largely (but not exclusively) placed on the interviewee - as the occupant of the dominant social roles investigated at the outset of the wider study outlined below. Interviews with development actors (including developers, builders, private planning and/or design consultants) will be highlighted for the interpretative value they provide in identifying and conceptualising the nature of the local development culture in Toronto, and in particular the conditions which it could be argued promoted the proliferation of New Urbanism (Moore 2013).

New Urbanism is a design and planning movement characterised by the revival of 'traditionalist' architecture and design which seeks 'to promote compact, mixed-use, walkable and reasonably self-contained communities (Grant 2006 p. 3). Much critical academic and practice-based attention has been directed at this form of development 
for its dubious grafting of ideological norms and principles onto seemingly benign design characteristics (Beauregard 2002). The fiercest critiques have labelled New Urbanism as culturally and financially exclusionary or elitist (see Grant 2006). In design terms, it has often been chided for promising radical suburban retrofitting by challenging modernist sprawl, but delivering on the ground yet more cookie-cutter housing tracts - leading some to dub it the 'new suburbanism' (Lehrer and Milgrom 1996; Grant 2002). For a useful review of New Urbanism's emergence, proliferation and influence (particularly in North America) see Grant 2006. For the intentions of this paper it is important to acknowledge that New Urbanism has proliferated in the greater Toronto area since the early 1990s, beginning with a few high-profile prototype communities and has subsequently become noted as the largest concentration of New Urbanist projects in the world (Gordon and Taminga 2002: Skaburskis 2006).

New Urbanism in and around Toronto is both an urban and suburban phenomenon, with examples observable in greenfield communities and brownfield infill projects. The field of development actors involved with projects in both contexts has elsewhere (Moore 2012) been shown to be permeable (i.e. across the greenfield/brownfield divide), yet practices are contingent upon hyper-local variability in market acceptance of alternative designs (including higher density products and rear-laneways for example) and a political will to endorse New Urbanism as an urban development policy idea at the Provincial and municipal level (See Moore 2010, 2012, 2013). The proliferation of New Urbanism in the Toronto area has fundamentally been a process 
of typification of one development option as $a$ if not the best practice; itself a process of abstraction that involves a complex cultural power struggle inciting early adopters, late adopters, partial adopters and non-adopters. The outcome, according to Bentley (1999 p.64) 'depends on the particular strategies and tactics deployed by the parties involved, and on the alliances that develop between them.' The representation of New Urbanism as a best practice has been accompanied by the affirmation of ideological supports for certain strategies, beliefs and desires (such as sustainability, community and efficiency) over and above others, securing compliance amongst development actors to New Urbanism's dominance (Lukes 2005). Thus the story of New Urbanism in Toronto conceals the power dynamics of negotiation and collaboration that promoted this particular development agenda winning out (Flyvberg 2002) over alternative development forms. What follows is an attempt to demonstrate the need to unpack the individual and collective rationalisations that constrained development actors to identify New Urbanism as an acknowledged way of doing things, thus establishing it as part of their social order or development culture. It is argued that cues for such an understanding of development actor practices are germane to the research interview itself, and as such should not be bracketed out of the analysis in favour of post-hoc outcome-oriented interpretations all-too-often the norm in planning and development research. The interview itself becomes a productive point of departure for analysing power dynamics of specific practices and observing 'the little things' (Flyvberg 2004) which help theorise how and why New Urbanism became best practice in Toronto. 
This analysis draws to a significant extent on the field of social psychology, and in particular the work of Mark Leary (1996; Leary and Kowalski, 1990). At the same time, it seeks to build on the challenges set by Cairns (2008) for 'theorizing the built environment at the micro-level, taking account of the contextual needs, values and beliefs of involved actors, whilst drawing upon meta-theories that provide generalised and objective knowledge drawn from other relevant research contexts' (p. 282). This paper's focus on the micro-level interactions and micro-geographies (Elwood and Martin, 2000; Sin, 2003) of the research interview illustrates how researchers might think through issues of research design, reconsider common methods, and reflect on the processes of empirical data analysis in order to enrich enquiries of the specificity of built environment actors, institutions and practices.

\section{Researching development actors}

To suggest there is a dearth of methodological consideration for the specificity of researching built environment practitioners is not to say that they are under researched; far from it. There is a vast literature detailing the behaviours and attitudes of planners, designers and developers in relation to various market and regulatory conditions (cf. Ball, 2006; Healey, 1998; Ambrose, 1986; Wilkinson and Reed, 2008; Adams, 1994; Adams and Tiesdell, 2010; D’Arcy and Keogh, 2002; Mohamed, 2006) as well as institutionalist studies of developer practices and the social organisation of property and building businesses and networks (cf. Healey, 1991; 1992; Ball, 1998; 2002a; 2002b; Guy and Henneberry, 2000; 2002a; 2002b; Guy, 2002; Wellings, 2006; Doak and Karadimitriou, 2007; de Magalhaes, 2002; 
Hawkesworth and Imrie, 2008). Very few researchers articulate, however, as part of their analytical process the implications of their methodological approach in the ultimate outputs ${ }^{2}$. Or rather, they rarely convey this to their readers because word limits and the need to adequately present the substantive content of a project makes unpacking methodologies in exhaustive detail impractical.

There are perhaps quite obvious reasons for the lack of methodologically-based literature on researching built environment professionals and practitioners. First and foremost, there is no unified 'group' as such to be researched. Nor does this paper suggest there should be. Built environment practitioners span a wide range of skill sets, educational training, employment structures and cultural orientations, whilst also demonstrating a gendered imbalance (cf. Greed, 2000; Wilkinson and Morton, 2007). Interviewees and key contacts run the gamut from manual labourers to big business elites, high-profile design professionals and city government policy managers and myriad consultants. Understandably, along with each sub-category of actor comes different challenges for negotiating contact and gaining access to conduct interviews in a variety of spatial settings (Elwood and Martin, 2000; Sin, 2003) - from the downtown project management and sales office to the development firm head offices located in suburban industrial estates, to the plush live-work lofts of high-flying internationally renowned designers.

As McDowell (1998) noted, the impact of biographical profile is more difficult to unpack than it is to identify. Once 'in the door' the intersections of age, gender, 
ethnicity, education, employment history and personal connections all take on more concrete resonance in defining the interviewer-interviewee status and the rapport that develops. Particularly noteworthy is the extent to which interviewers may alter their visual and verbal demeanour to establish a rapport which would support progression of the interview. Similar to McDowell's (1998) and Desmond's (2004) experiences with interviewing elites it is common as an interviewer to straddle at least two strategies of self-presentation - as one of 'them' (i.e. a professional 'expert') and as a naive student/layperson (i.e. innocuous and impressionable; sometimes giving into gender and other dominant stereotypes). From this brief reflection, it becomes evident that the interview process, and its analysis, must be seen from the perspective of situated knowledge construction. That is to say, seen as a function of the contingent nature of researcher access (Ward and Jones, 1999) and the interplay of individual strategies for monitoring and managing the impressions of self and other.

It is crucial to state that this paper does not make the claim that interviewing built environment practitioners is a special case methodologically in the social sciences; there is insufficient evidence here or elsewhere to suggest the built environment field is distinctive with regard to how to approach and analyse interviews. Rather, what the paper argues quite simply is that the research interview, a method already deeply entrenched in norms of good research practice in the built environment, can and should be used more instrumentally to enhance our understanding of the development industry via finer-grained coding for key interpretive registers that assist to define dominant local development cultures. The propensity in planning and development 
research is to focus on the 'big questions' and problems (such as sustainability, climate change, affordability etc.) whilst the details and particulars of how answers to these big questions are reached are extracted and put to the side (cf Flyvberg 2004) in favour of normative prescriptions for improvement (which is not the case in other social science disciplines such as human geography and urban sociology). This is understandable in an era when checklists and toolkits of best practice are demanded as a means to meet (minimum) policy and regulatory standards of design, building and construction. But the danger of this approach is the glossing over of processes and interactions which precipitate the domination of some knowledge or practices over others, with little if any democratic debate or at least not a public accounting of such debates.

This is particularly important when one considers the documented lack of understanding on the part of policymakers of how the private development sector in particular operates (Guy and Henneberry 2002b; Adams et al 2012, Henneberry and Parris 2013). A reliance on secondary or indirect evidence (Guy and Henneberry $2002 b$ ), the proprietary nature of finance and business models, presumptions of a universal development 'process', alongside a general lack of knowledge sharing within a competitive sector, all potentially distort outsider perceptions of the industry. The implications of this are complex. The tendency, according to Coiacetto (2000 p. 353 ) is to treat the development industry as an 'undifferentiated whole'. The lack of detailed knowledge of the sector suggests policymakers may be making unrealistic or untenable assumptions about the motivations, behaviours and capabilities of firms, 
consortiums, and individuals at the forefront of the industry - the oft-termed 'leaders' charged with the real policy implementation on the ground and those labelled as 'laggards' in post-hoc evaluations of policy (in)effectiveness. Adams et al (2012) in their study of the Scottish Executive's perceptions of, and policy stances towards developers between 1999 and 2007, for example, identified a severe schism between a policymaker construction of the 'notional property developer' as a compliant partner in policy delivery and the reality of individual developer motivations and the extent of variation across the sector. They concluded by arguing for a 'more thorough understanding of the development industry, and particularly the cultural differences between different types of developer, as a pre-requisite for more effective policymaking' (Adams et al 2012 p. 2593). This paper contributes a complementary (rather than primary) methodological approach in support of Adams et al's (2012) call for improving the general understanding of development cultures and Henneberry and Parris' (2013) argument for the use of project ecologies as an analytical framework for researching local development networks. The latter emphasises the contingent and emergent causes and characteristics of projects and offers an approach which assumes the heterogeneity of development and development actors at various sociospatial scales (Henneberry and Parris 2013).

At least in part this can be achieved by the coding of interviews for norms and tactics which demonstrate disclosure of cognition and coordination practices (Thévenot 2007), which serve to stabilise (or destabilise) certain knowledge claims (such as New Urbanism is best practice) across a cross-section of development actors. In particular, this makes the analysis of when and how interviewees conform, challenge 
or transcend their assumed development actor prototypes or 'notional' actor correspondence (Adams et al 2012) very revealing. A specific example of this is explored later in the paper wherein it is detailed how interviews were used to query rather than reify the a priori categories of 'public' and 'private' in development processes (see also Author 2012), making plain the misconceptions, bias and distortions that perpetuate the notion of a universal development process. In this case, this coding lead the researcher to ask deeper questions of how these particular findings influenced or indeed challenged any existing or emerging theorisation of the proliferation of New Urbanism has in Toronto

It is important to state that the original research from which this paper emerged was not structured around an ethnomethodological approach, nor did it emphasise the utility of a phenomenological interpretation of the interview as data. The wider project, which investigated the proliferation of New Urbanism in Toronto, Canada, involved the empirical analysis of four-mastered planned communities. Two were located on urban brownfield sites in the City of Toronto and two were located on greenfield sites in the suburban fringe. Fifty-seven in-depth, face-to-face, semistructured interviews were undertaken with key development actors (public and private) involved in the conception, planning and delivery of the project sites. The empirical analysis is detailed fully elsewhere (see Author 2010; Author 2012 and 2013). The original emphasis was on the relational networks of actors and a snowballing sampling method was employed. Characteristics of interviewees (and the intersection of these with the interviewer's characteristics) such as gender, race, age, 
previous work experience, personal histories and sensitivities to the locale and its changes over time were coded along with a priori categorisation of them as particular actor 'types', such as developer, housebuilder, planner, designer, architect etc. As the research progressed these distinct categories became increasingly problematic and the recognition of role or social type-hybridity prompted a stronger emphasis on thematic codes over descriptive codes based on actor rolecorrespondence. Research memos, along with the transcripts notated both interviewer and interviewee characteristics and behaviour, but as always the interpretation of the significance of these to the wider research is the researcher's own. The following section discusses how this interpretation of interview conduct can be included in the analysis of qualitative interviews and demonstrates through example the explanatory insights that it can deliver.

\section{Impression management in the research interview}

Face-to-face research interviews are a particularly germane forum for unpacking the desire to control the conduct of others, especially by negotiating the best possible 'responsive treatment' (Goffman, 1959, p. 15) of ourselves. As researchers, then, how one presents one's self or what one's impression 'gives off', and conversely, what one 'reads off' from an interview subjects' performance, matters. These interactions of self-interest undoubtedly 'influence the definition of the situation' (Goffman, 1959, p. 17) within which they occur. 
Everyone monitors the impression they perceive to be forming in interaction with others, but one does not always engage in conscious impression management or alter one's self-presentational behaviours (Leary, 1996). In some situations however, like an interview, 'people become motivated to control how others perceive them' (Leary, 1996, p. 53). In such settings people begin to act in ways which lead others to form certain impressions. These may be either attributive tactics (i.e. conveying possession of positive attributes) or repudiative tactics (denying the possession of negative characteristics) (cf. Roth et al, 1988; Leary, 1996). These can appear in spoken word through the use of self-description, expressions of particular attitudes that connote the possession of certain positive attributes or statements which explain one's behaviour in ways that support a particular social image. These tactics might be supported by memory contrivances (e.g. anecdotal stories of childhood experiences etc.), nonverbal behaviours (e.g. body gestures), social associations and disassociations (e.g. identifying self as pro-New Urbanism or sceptical of its emergence and impact), and manipulations of the physical environment where the interview is taking place to support positive self-presentation (e.g. absence of computers, presence of project plans and strategic reference to other plans and briefs of projects with 'similar features'). Much of these cues suggest to the researcher if and when an interviewee feels the need to conform and comply with dominant social norms and the perceived preferences of the others.

The motivation for such behaviour alterations serves three primary functions:

1. to serve as a means of interpersonal influence;

2. to enhance the construction of personal identity and maintain self-esteem; and 
3. to promote positive emotions (Leary 1996, p. 40).

The specificity of the interview setting fits into the classic interpretation of Goffman's notion of self-presentation, as a mode of social influence precipitated by a desire to maintain or augment individual power in social interactions or relationships (Jones and Pittman, 1982). Power here simply refers to the ability to intentionally produce desired changes in other people. In Leary's (1996) words: 'people can often influence others to respond to them in desired ways - that is, they can exercise power over others - by presenting certain impressions of themselves' (p. 42). This bears strong similarities with the intentions of an interviewer driven to 'get the data' and willing to act in the most appropriate manner to secure it. The interviewer may presume to enter the interview in a more powerful position (i.e. knowing what is to be discussed), but there is always the endemic dependence of the interviewer on the interviewee's willingness to fully participate to the depth of disclosure that the researcher requires to fit his/her brief.

Leary and Kowalski (1990) identify three factors that motivate us to manage others' impressions of ourselves: the goal-relevance of impressions formed by others; the value of desired goals being particularly high; the existence of discrepancies between the desired impression held by others and the perceived image others actually hold. In the Toronto interviews, participants attempted to establish with the interviewer a position on New Urbanism and how their work aligns or distances itself from this 
label. Developers and builders (and developer-builders) were more likely to draw out the similarities between their projects and features associated with New Urbanism.

I was very familiar with the concept, and in fact it was stuff that I was building in the inner city already - we built a lot of redevelopment projects where laneways were the way the city was built. I guess the rest of the building community is still struggling with understanding the concept of New Urbanism, what it represents and what market you need to sell it to'

If you look at the New Urbanism books, the goals and aspirations, we believe we fulfill them in multiple communities. We have built our version of New Urbanism.'

Hired private consultants (i.e. architects, designers, planners) on the other hand quite often sought to distance themselves from what could be labelled New Urbanism, suggesting it was a passing fad. Any continuing association with the label presumably might undermine their reputation as cutting edge in the field.

'Most of our projects are urban ones, you won't find us doing anymore of these...this is NOT a New Urbanism firm'

If we were reliant on New Urbanist projects we would be out of business. Generally, developers are pursuing it here only if they have to, and are being told they have to, but I know very few who want to or do unless they have to.' 
Leary (1996, p. 60) argues that 'as long as people think they are making the kind of impression they want to make, impression-motivation should be minimal.' But once someone becomes aware that others are not forming the desired impressions, they will be motivated to impression manage. No doubt, both as interviewer and interviewee, one enters the meeting desiring to make a particular impression in line with either one's personal or professional 'stake' in the research subject area, and yet much of what one says and does through the course of the conversation is performed unconsciously. In the interviews with New Urbanism producers the most common self-monitoring registers seemed to be employed to counter any perceived discrepancy between the interviewer's assessment of the interviewee's role or position in the field (e.g. as 'developer', 'builder', ' planner', 'designer' etc.) and their preferred self-identification (e.g. as 'visionary', 'reformer', 'innovator', 'radical' or perhaps 'realist'). This manifested within oscillating demonstrations of: modesty and aggrandising; playing dumb and knowing it all; exemplifying the virtuous and off-the-record pre-emptive disclosures - often all within a single interview. Table 1 summarises these norms of self-presentation and provides indicative (but not exhaustive) examples from interviews with different individuals across the three dominant self-categorisations of development actor.

\section{INSERT TABLE 1 ABOUT HERE}


Table 1 is notable for the contrast in the use of self-monitoring registers across the interviewee-identified development actor types. Developers were more inclined to present their 'visionary' aptitude and knowledge of the 'bigger picture'; builders identified themselves as the simpletons of the industry; and consultants were the most likely to challenge the value of the interviewer's research framework.

The self-monitoring registers and the common tactics can be better understood by considering two norms of self-presentation underpinning the context-specific social setting of the interview - the basis of both being that people should present themselves as others they are interacting with are presenting themselves (Leary, 1996). The positivity norm, for example, demands that each person presents themselves in just as positive a light as the person they are interacting with and the depth of disclosure norm dictates that one monitors the appropriate degree of personal disclosure and emotion demonstrated by others, and behaves in kind (Leary, 1996, p. 70-71).

Positivity and depth of disclosure are both, however, individually-motivated norms of common practice, undertaken to avoid standing out or not fitting in, and as important in the context of an interview as in casual small talk in the doctor's waiting room. What differentiate these types of interactions are the context-specific norms of institutionalised practice existing amongst built environment practitioners (cf. Bentley 1999; Fischler 1995). Thus social role, or more accurately position, within building and development cultures must be considered. This acknowledges that there 
are sets of behaviours associated with certain social positions which translate into personal and collective expectations that a particular actor identified as occupying a social position or role should possess certain attributes and present him/herself in a particular way.

Thus, the interview process is not simply a researcher's attempt to gain insight into the social 'roles' of built environment practitioners but rather an effective lens to interpret the contingency or hybridity of 'positions' within the social field of the built environment. This hybridity is brokered by multiple aspects of personal character and identity-formation (including gender, ethnicity, age, and class amongst others); and only some of these factors are knowable through the research interview. At any one time the interviewer or interviewee has the potential to appear to the other as the 'natural occupant' of a particular position in the field (Markham 2011). For example, at the time of this research the author was a PhD student, in McDowell's (1998) language 'naïve', 'innocuous' and 'impressionable' but she also had previous professional experience working in the field of planning and environmental policy in the local context. As such, she was at least partially a member of the professional field, but not generally perceived as a peer or competitor. Some interviewees oriented themselves to this shared membership and subsequently exposed particular categories by which they enacted and assessed their own and others practices in the professional field (Markham 2011). Others oriented themselves more towards what they perceived to be common academic interests or their own personal education trajectories and tended to gloss over what they implied were 'boring' or mundane 'technical details' 
of their daily practice, assuming the researcher would not find these interesting. Still others used gender-specific stereotypes variably, and perhaps unconsciously, to neutralise or shift the power dynamic within the interview setting.

Both interviewer and interviewees entered into a discursive process objectifying the development field being variably oriented to its demands. As Markham notes,

Some need to adapt more than others, depending on their personal trajectories of education, class, geography and so on - the performance of which is structured, ritualized and progressively embodied: that is, experienced as a personal character rather than something requiring conscious calculation or effortful enactment. Peers and audiences alike come to perceive this positiontaker not as an effective performer of required values, but the natural repository of these values $(2011$, p. 571).

Leary, similarly emphasises that such 'role-determined self-presentation is governed to some extent by the process of prototype correspondence' (1996, p. 81). Prototype correspondence refers to the norm for people to categorise themselves and others according to socially-determined cognitive prototypes by which they measure relative association with a particular social position or role (Leary, 1996). In impression management terms, most people will attempt to demonstrate a strong match between the prototype and their own behaviour. That is, of course, if the prototype is a positive one, and one which does not obviously conflict with other role-determined selfpresentation norms.

Conflicting social roles or positions of a single individual - perhaps those of a local politician who is also a private landowner and developer - can thus cause considerable discomfort, if and when the roles demand conformity with incompatible 
self-presentation norms. One can imagine that such an individual would find an academic research interview a significant crisis of self-presentation, wherein the interviewer is probing his/her personal and professional agency in either policy or practice, or both. This was indeed the case with one developer, who on a personal level and as a local resident detested the New Urbanist housing his company was producing in his hometown, but on the professional and commercial basis he had to maintain the firm's commitment to the New Urbanism 'vision'.

'My vision is not this. If I was moving here today I would expect to live in a single detached home with garage in the front, that is because that is what I am accustomed to or what my preference would be; that is not what we are building'.

Add to this personal dilemma the catch-22 of self-presentation: 'the more important it is for an individual to impress a target, the more likely the target is to be sceptical of the truthfulness of the individual's self-presentations' (Leary, 1996, p. 107). One can see the research interview as a considerably demanding social encounter for a development actor intent on defending his/her work practices and reputation within the field whilst demonstrating a social conscience and being likable. For the much maligned 'developer', interviews with academic researchers provide a new forum to work against negative stereotypes (e.g. 'all it takes is one bad apple' (Interview Homebuilder's Federation Representative)); but equally they may lead them into unfamiliar social territory, thus provoking the inclination (consciously or not) to utilise multiple impression management tactics. 


\section{Why bother coding for impression management?}

The inclusion of codes for impression management tactics and norms of selfpresentation in parallel with the substantive themes emerging from the interview data revealed a significant amount of detail on the ideological supports and practical vocabulary that development actors use to make sense of what they do on a daily basis. Particularly revealing were episodes of self-description, attitude expressions, attributional statements, social associations, conformity and compliance and the oscillation between modesty and aggrandising, playing dumb and knowing it all, and to a lesser extent exemplifying the virtuous and instances of pre-emptive disclosure.

These behavioural registers were crucial in the identification of a significant trend in Toronto's planning and development trajectory and answered in part why New Urbanism, specifically, had proliferated in this context. This was the convergence of so called 'public' and 'private' discourses of the common good and market success. The theme of public v. private was identified early in the data collection stage as a complex terrain. Through the evaluation of interviewee statements and their selfalignments as either 'public' or 'private' actors and their reflections (including associations and disassociations uttered in the interview context) on the 'other' in each respective case revealed contradiction between prototype (or social role) correspondence, perceptions and practices. This challenged a tendency in the literature and on the part of the researcher to essentialise the pursuit of the public good as the domain of the public sector, to deny the market-led orientation in public 
planning and to be cynical of any claims within the development industry to be in pursuit of the public good. The significant finding (covered in detail in Author 2012) was not just the mere swapping of so-called public and private motivations and values, but rather the identification of a shift in the patterns of actor hybridity (Pieterse 2001); 'the relative contingency of the boundaries effecting asymmetries of power and influence within a local development culture' (Moore 2012, p. 591). The convergence of development actor rationalities and practices across the assumed public-private divide pushed the research to new areas of enquiry - not just the question of what is public and what is private but why and how the discourse is variably normalised and perpetuated within the development field itself. This supported a stronger claim that academic study of urban development should not reify the discursive categories of public and private but 'rather pay closer attention to the situated conditions within which the discourse finds resonance' (Moore 2012, p.593). One such context is the academic interview. Through this supplemental analysis of self-presentation norms and tactics the researcher became self-aware of the compulsion to a priori categorise development actors, processes and products as public or private.

This reflective acknowledgement led further to questioning whether or not the presumption of public and private tendencies suggested New Urbanism was exceptional in terms of residential development processes and cultural practices; or was it merely a new label for otherwise conventional development practices? Overall the complementary interview data analysis provided a deeper engagement with the 
specific practices of development actors and supported original theorisation on how the specific local development culture was constituted, and the wider implications for policy and practice. The significance of this insight into a wider hybridity consciousness in development practices in Toronto suggested that the local development culture was characterised by an increased mobility of actors, ideas and motivations and a shared vocabulary wherein public and private positionality was less specific and determinable. This directed research into the patterns of role-hybridity affecting local development processes and outcomes to be unpacked project-byproject looking for the conditions which supported or opposed the take-up of New Urbanism over and above other alternative forms. It also meant that the impulse to delineate the process by the conventional distinctions of public and private was confronted and challenged. The contrast of projects where New Urbanism 'won out' with those where it was less successfully realised on the ground were critical to understanding the influence that a convergence in so called 'public' or 'private' concern for local market acceptance of new housing forms, products and schemes had on process and outcome. At the same time this generated a rich database on development actor rationalisations and institutional practices which were used to theorise how New Urbanism became variably accepted as a 'good' by different development actors.

\section{Conclusions}

The research interview, then, is a site for context-specific norms of practice and behaviour; it is a social situation which can motivate participants (both interviewer 
and interviewee) to attempt to control how the other perceives them. As a mode of social influence, the interview is an exercise in power and communication; one that demonstrates the extent to which impression monitoring and the enactment of selfpresentation tactics to affirm or challenge others' perceptions are a constant and innate feature of social research. Yet, there is a propensity in built environment research to concentrate on the physical outputs of building processes and the economic structures (e.g. 'market forces') which support them. This prompts Davis (2006) to argue that 'what is lacking is a general framework of thought in which all of these things are related... a framework in which the process of building production as a whole is understood in terms of the various components that make it up' (p. 3).

This is further supported by Koskela's statement that 'theory-building in the built environment tends to be fragmented, under-resourced and explored from the limited perspectives of individual disciplines or interest groups within the construction/property industry' (2008, p. 211). These observations underscore the creative tension which exists between academic calls for a common discourse for theories of the built environment (Rabeneck, 2008) and demands for more methodological rigour and inter-disciplinarity (rather than multi-disciplinarity) of scope in practice-oriented research (Gann, 2001).

Cairns (2008, p. 281) suggests that:

The complexity and ambiguity of the built environment is best understood in the multiple contexts of its design, construction, maintenance and occupation over time 
by means of an ambivalent process of theorizing at the local level that draws upon the broadest range of relevant theoretical constructs and empirical examples.

Thus it is at the context-specific, local level - within the sphere of practices - where interactions between built environment actors demonstrate the range of opinions, perceptions and norms of practice (cf. Cuff, 1991) that are 'informed by different theoretical and conceptual standpoints, underpinned by different beliefs and values, and influenced by the power relations and the politics of those involved' (Cairns, 2008, p. 281). In other words, exactly the things researchers of the built environment attempt to better understand through interviews. Acknowledging and interpreting the self-presentation dynamics of built environment professionals in interaction with academic researchers thus becomes part of, rather than an externality to, an holistic approach to understanding the normalisation of professional practices into rationalities of 'how things are done'. For example, noting the propensity to 'play dumb' amongst those in the homebuilding/development profession can help situate (and problematize) dominant arguments in built environment literature that describe the industry as the 'snail' of innovation (Ball 1999) and helps contextualise relatively low social and political expectations for design and sustainability leadership from the mainstream homebuilding sector.

More directly in relation to the research on New Urbanism in Toronto, the contradictions in prototype correspondence and skewed perceptions and rationalisations amongst so-called 'public' and 'private' development actors threw the assumed analytical categories into question and sparked original debate regarding the distinctiveness of this particular form of residential building provision. Research 
which attempts to unpack the nature of building or development cultures in particular contexts and through particular built forms, begins to unravel how this culture can predispose built environment actors to 'frame situations and problems in particular ways; that is to analyse them according to specific categories, to synthesise them into specific structures, and to represent them in specific verbal, graphic or numerical ways' (Fischler, 1995, p. 21). In this way, the interview process can itself become an interpretive vehicle to explore how people 'are subject to explicit constraints and they are limited in their deeds and words by all that is taken for granted as belonging to the order of things by their culture' (Fischler, 1995, p. 14). The ability to interpret constraint-based practices provides researchers with a relational perspective on the normalisation of forms and processes in the built environment.

The intent of this paper is not to derive recommendations on 'how' to inculcate reflexivity and situated knowledge production into standard reports on the built environment, nor to suggest that every journal article should incorporate a discussion of the phenomenology of the research interview process via critical discourse analysis. Rather this paper has asserted that if the self-presentational tactics of impression management imbued within the research interview are dismissed as insignificant and no attempt is made to embed these within the analytical frameworks, the critical ability to identify and analyse the relationships between practices, perceptions and norm formation within the professional domains of the built environment is unnecessarily constrained. 
Reflexive understanding of the impact academic inquiry plays in the ambiguous assemblage of what constitutes, affects and represents the built environment is necessary to avoid the epistemological blinkering that simply 'writing up' findings often engenders (cf. Richardson 2000; McCann and Ward 2012). As McCann and Ward have recently stated, writing up implies 'a post hoc, mechanistic, and transparent reporting of findings' whilst academic research design and writing can and should 'encourage analysis and expression in and through the process of representation' (2012, p. 50). This paper supports this position by suggesting the need not only to acknowledge research design decisions about which actors, policies, projects and practices to study (McCann and Ward 2012) but also for a finer-grained consideration of the impression motivation tactics and self-presentation norms endemic to qualitative interviews, as a key method used to develop critical insights on dominant and emergent development cultures. The 'nexus of doings and sayings' (Schatzki, 1996, p. 89) of researchers and subjects in the context of the interview can effectively be 'rematerialized' (Markham 2011, p. 569) beyond the symbolic performance of the encounter to reflect on common (and not-so-common) ideological registers and relational logics (e.g. the essentialism v. contingency of the publicprivate dichotomy) in the field of practices across the diversity of built environment practitioners. 


\section{References}

Adams, D. (1994) Urban Planning and the Development Process, UCL Press, London.

Adams, D., Croudace, R. And Tiesdell, S. (2012) Exploring the 'Notional Property Developer' as a Policy Construct Urban Studies 49(12), 2577-2596.

Adams, D. and Tiesdell, S. (2010) Planners as market actors: rethinking state-market relations in land and property. Planning Theory \& Practice, 11, 187-207.

Amaratunga, D., Baldry, D., Sarshar, M. and Newton, R. (2002) Quantitative and qualitative research in the built environment: application of 'mixed' research approach. Work Study 51(1), 17-31.

Ambrose, P. (1986) Whatever Happened to Planning?, Methuen, London.

Ball, M. (1998) Institutions in British Property Research: a review. Urban Studies 35(9), 1501-1517.

Ball, M. (1999) Chasing a Snail: Innovation and Housebuilding Firms' Strategies. Housing Studies 14(1), 9-22. 
Ball, M. (2002a) Cultural explanation of regional property markets: a critique. Urban Studies 39(8), 1453-1469.

Ball, M. (2002b) The organisation of property development professions and practices, in S. Guy and J. Henneberry (eds.): Development and Developers: perspectives on property, Blackwell Science Ltd, Oxford, pp. 115-136.

Ball, M. (2006) Markets \& Institutions in Real Estate \& Construction, Blackwell, Oxford.

Beauregard, R. (2002) New Urbanism: ambiguous certainties. Journal of Architectural and Planning Research 19(3), 181-194.

Bentley, I. (1999) Urban Transformations: power, people and urban design, Routledge, London.

Bourdieu, P. (2005) The political field, the social science field and the journalistic field, in R. Bension and E. Neveu (eds.): Bourdieu and the Journalistic Field, Cambridge, Polity Press, pp. 29-47.

Briggs, C. (2003) Interviewing, Power/Knowledge and Social Inequality, in J. Gubrium and J. Holstein, J. (eds.): Inside Interviewing: new lenses, new concerns, Thousand Oaks, California and London, Sage, pp. 495-506. 
Cairns, G. (2008) Advocating an ambivalent approach to theorizing the built environment. Building Research \& Information 36(3), 280-289.

Coiacetto, E. (2000) 'Places shape place shapers? Real estate developers' outlooks concerning community, planning and development differ between places’ Planning Practice \& Research 15, 347-353.

Cuff, D. (1991) Architecture: The Story of Practice, MIT Press, Cambridge MA.

D’Arcy, E. and Keogh, G. (2002) The market context of property development activities, in S. Guy and J. Henneberry (eds.): Development and Developers: perspectives on property, Blackwell Science Ltd, Oxford:, pp.19-34.

Davis, H. (2006) The Culture of Building, Oxford University Press, New York.

de Magalhaes, C. (2002) Global players and the re-shaping of local property markets: global pressures and local reactions, in S. Guy and J. Henneberry (eds.): Development and Developers: perspectives on property, Blackwell Science Ltd, Oxford, pp. 224-246.

Desmond, M. (2004) Methodological challenges posed in studying an elite in the field. Area 36(3), 262-269. 
Doak, J. and Karadimitriou, N. (2007) (Re)development, complexity and networks: a framework for research. Urban Studies 44(2), 209-229.

Elwood, S. and Martin, D. (2000) Placing interviews: locations and scales of power in qualitative research. The Professional Geographer 52(4), 649-657.

Fischler, R. (1995) Strategy and History in Professional Practice: planning as world making, in H. Ligget and D. Perry (eds.): Spatial Practices: critical explorations in social/spatial theory Sage, London, pp. 13-58.

Flyvberg, B. (2006) Five Misunderstandings About Case-Study Research. Qualitative Inquiry 12(2), 219-245.

Flyvberg, B. (2004) Phronetic planning research: theoretical and methodological reflections. Planning Theory \& Practice 5(3), 283-306.

Flyvberg, B. (2002) Bringing Power to Planning Research: One Researcher's Praxis Story. Journal of Planning Education and Research 21, 353-366.

Gann, D. (2001) Putting academic ideas into practice: technological progress and the absorptive capacity of construction organizations. Construction Management and Economics 19, 321-330. 
Goffman, E. (1959) Presentation of Self in Every Day Life, Penguin Books Ltd., Harmondsworth, Middlesex.

Gordon, D. and Taminga, K. (2002) Large-scale Traditional Neighbourhood Development and Pre-emptive Ecosystem Planning: the Markham Experiences, 1989-2001. Journal of Urban Design 7(2), 321-340.

Grant, J. (2006) Planning the Good Community: New Urbanism in Theory and Practice. Routledge, London.

Grant, J. (2002) From 'sugar cookies' to 'gingerbread men': conformity in suburban design. Planners Network Bulleting 151, 10-13.

Greed, C. (2000) Women in the construction professions: achieving a critical mass. Gender, Work and Organization 7(3), 181-196.

Gubrium, J. and Holstein, J. (eds.) (2003) Inside Interviewing: new lenses, new concerns, Sage, Thousand Oaks, California and London.

Guy, S. (2002) Developing interests: environmental innovation and the social organisation of the property business, in S. Guy and J. Henneberry (eds.): 
Development and Developers: perspectives on property, Blackwell Science Ltd, Oxford, pp. 247-266.

Guy, S. and Henneberry, J. (2000) Understanding urban development processes: integrating the economic and the social in property research. Urban Studies 37(13), 2399-2416.

Guy, S. and Henneberry, J. (2002a) Bridging the Divide? Complementary Perspectives on Property. Urban Studies 39(8), 1471-1478.

Guy S. and Henneberry, J. (eds.) (2002b) Development and Developers: perspectives on property, Blackwell Science Ltd, Oxford.

Haigh, R. (2008) Chapter 10 Interviews: A negotiated partnership, in A. Knight and L. Ruddock (eds.): Advanced Research Methods in the Built Environment, WileyBlackwell Chichester, pp. 51-63.

Hawkesworth, M. and Imrie, R. (2008) Organisational change in systems of building regulation and control: illustrations from the English context. Environment and Planning B 36(3), 552-567.

Healey, P. (1991) Models of the development process: a review. Journal of Property Research 8, 219-238. 
Healey, P. (1992) An institutional model of the development process. Journal of Property Research 9, 33-44.

Healey, P. (1998) Regulating property development and the capacity of the development industry. Journal of Property Research 15(3), 211-227.

Henneberry, J. and Parris, S. (2013) The embedded developer: using project ecologies to analyse local property development networks. Town Planning Review 84(2), 227249.

Jones, E. and Pitman, T. (1982) Toward a general theory of strategic selfpresentation, in J. Suls (ed.): Psychological Perspectives on the self, Vol. 1, Erlbaum, Hillsdale NJ, pp. 231-262.

Knight, A. and Rudduck, L. (eds.) (2008) Advanced Research Methods in the Built Environment Wiley-Blackwell, Chichester.

Koskela, L. (2008) Is theory of the building environment needed? Building Research \& Information 36(3), 211-215. 
Leary, M. (1996) Self-Presentation: Impression Management and Interpersonal Behaviour, Westview Press, Boulder CO.

Leary, M. and Kowalski, R. (1990) Impression Management: A literature review and two-component model. Psychological Bulletin 107(1), 34-47.

Lehrer, U. and Milgrom, R. (1996) New (sub)urbanism: countersprawl or repackaging the product. Capital Nature Society 7(2), 49-64.

Lukes, S. (2005) Power: A Radical View, Palgrave Macmillan, Basingstoke.

Markham, T. (2011) The political phenomenology of war reporting. Journalism 12(5), 567-585.

McCann, E. and Ward, K. (2012) Assembling urbanism: following policies and 'studying through' the sites and situations of policy making. Environment and Planning A 44(6), 42-51.

McDowell, L. (1998) Elites in the City of London: some methodological considerations. Environment and Planning A 30(12), 2133-2146. 
Mohamed, R. (2006) The psychology of residential developers: lessons from behavioural economics and additional explanations for satisficing. Journal of Planning Education and Research 26, 28-37.

Moore, S. (2013) What's Wrong with Best Practice? Questioning the Typification of New Urbanism. Urban Studies 50(11), 2371-2387.

Moore, S. (2012) Re-evaluating 'public' and 'private' in local development cultures: converging vocabularies of public good and market success in Toronto's New Urbanism. Town Planning Review 83(5), 575-595.

Moore, S. (2010) 'More Toronto, naturally' but ‘too strange for Orangeville': deuniversalising New Urbanism in Greater Toronto. Cities 27, 103-113.

Orum, A., Feagin, J. and Sjorberg, G., (eds.) (1991) A Case for the Case Study, The University of North Carolina Press, London.

Pierterse, J. (2001) Hybridity, so what? The anti-hybridity backlash and the riddles of recognition, Theory, Culture \& Society 18, 219-45.

Pryke, M. and Du Gay, P. (2002) Property companies and the remaking of markets: stories from the 1990s, in S. Guy and J. Henneberry (eds.): Development and Developers: perspectives on property, Blackwell Science Ltd, Oxford, pp. 267-284. 
Rabeneck, A. (2008) A sketch-plan for construction of built environment theory. Building Research \& Information 36(3), 269-279.

Richardson, L. (2000) Writing: a method of inquiry, in N. Denzin and Y. Lincoln (eds.): Handbook of Qualitative Research, Sage, Thousand Oaks, CA, pp. 923-948.

Roth, D., Harris, R. and Snyder, C. (1988) An individual differences measure of attributive and repudiative tactics of favourable self-presentation. Journal of Social and Cultural Psychology 6(2), 159-170.

Schatzki, T. (1996) Social Practice: A Wittgensteinian Approach to Human Activity and the Social, Cambridge, Cambridge University Press.

Sin, C. (2003) Interviewing in 'Place': the socio-spatial construction of interview data. Area 35(3), 305-312.

Skaburskis, A. (2006) New Urbanism and Sprawl: A Toronto Case Study. Journal of Planning Education and Research 25, 233-248.

Thévenot, L. (2007) The Plurality of Cognitive Formats and Engagements: moving between the familiar and the public European Journal of Social Theory 10(3), 409423. 
Ward, K. and Jones, M. (1999) Researching local elites: reflexivity, 'situatedness' and politico-temporal contingency. Geoforum 30(4), 301-312.

Wellings, F. (2006) British Housebuilders: history \& analysis, Blackwell, Oxford.

Wilkinson, S. and Morton, P. (2007) The emerging importance of feminist research paradigms in built environment research. Structural Survey 25(5), 408-417.

Wilkinson, S. and Reed, R. (2008) Property Development $5^{\text {th }}$ Edition, Routledge, London. 
Table 1: Common Self-monitoring registers (following Leary 1996)

\begin{tabular}{|c|c|c|}
\hline $\begin{array}{l}\text { Self- } \\
\text { Presentation } \\
\text { Norm } \\
\end{array}$ & Description & Examples from Interviews \\
\hline $\begin{array}{l}\text { Modesty v. } \\
\text { aggrandising }\end{array}$ & $\begin{array}{l}\text { This tension exists as the } \\
\text { trade-off between being } \\
\text { positively perceived and self- } \\
\text { inflating one's importance. } \\
\text { There is a pressure to } \\
\text { downplay achievements but } \\
\text { not to demonstrate low self } \\
\text { esteem or professional } \\
\text { shortcomings. }\end{array}$ & $\begin{array}{l}\text { Developer: } \\
\text { 'I am years ahead of the development } \\
\text { community from a thinking process, but does } \\
\text { that make me more money? Probably not, it } \\
\text { just makes me a better thinker.' } \\
\text { Homebuilder: } \\
\text { 'I don't know if we are innovators to be } \\
\text { honest. In today's world you want to get your } \\
\text { share of the market. But what we do, and you } \\
\text { just met my partner, we like to be a cut above } \\
\text { the rest'. } \\
\text { Design Consultant: } \\
\text { 'Well, ok I don't want to dwell too much on } \\
\text { the New Urbanism thing, because it has been } \\
\text { years since I have been involved. All I work } \\
\text { on now is in the hearts of cities. I am not } \\
\text { doing any suburban by choice.' }\end{array}$ \\
\hline $\begin{array}{l}\text { Playing dumb v. } \\
\text { knowing it all }\end{array}$ & $\begin{array}{l}\text { Downplaying personal } \\
\text { intelligence, skills, } \\
\text { knowledge or competence } \\
\text { because of perceived } \\
\text { preference for this from the } \\
\text { person one is interacting } \\
\text { with, allowing that person to } \\
\text { feel superior, or because it } \\
\text { limits chances of being } \\
\text { challenged. Others exert } \\
\text { effort to demonstrate their } \\
\text { superiority and expertise } \\
\text { over and above the skills, } \\
\text { knowledge, experience and } \\
\text { competence of the persona } \\
\text { they are interacting with. } \\
\text { This tension involves finding } \\
\text { a compromise between } \\
\text { likability and competence. }\end{array}$ & $\begin{array}{l}\text { Developer: } \\
\text { 'So that is in part my reticence with what you } \\
\text { are doing (studying), because the answers are } \\
\text { profoundly local and a merely a function of } \\
\text { the market, it's not really any more } \\
\text { complicated than that. } \\
\text { Homebuilder: } \\
\text { 'Again, I am just a dumb homebuilder, what } \\
\text { do I know, these are just observations.' } \\
\text { Planning Consultant: } \\
\text { 'I can see what you are trying to do with the } \\
\text { rubric of New Urbanism, but it may be just a } \\
\text { little bit of a red herring. I think the real issue } \\
\text { is about a balance between public and private } \\
\text { things as opposed to New Urbanism v. } \\
\text { whatever the contrary is.' }\end{array}$ \\
\hline $\begin{array}{l}\text { Exemplifying the } \\
\text { virtuous v. pre- } \\
\text { emptive disclosure }\end{array}$ & $\begin{array}{l}\text { Fostering images of self } \\
\text { associated with moral or } \\
\text { altruistic virtue (i.e. honesty, } \\
\text { integrity, generosity, } \\
\text { dedication, ingenuity, } \\
\text { creativity, self-sacrifice etc.). }\end{array}$ & $\begin{array}{l}\text { Developer: } \\
\text { 'Smart growth? I love it. Don't get me wrong } \\
\text { I use it as part of my marketing. If I have got } \\
\text { wireless connectivity, municipal transport at } \\
\text { the door step, these are things I sell along } \\
\text { with the fact that my homes as good as they } \\
\text { are built are also more sustainable than my } \\
\text { competition next door. So I use it to my } \\
\text { advantage because I am smart enough to } \\
\text { understand it and talk about it and not lie } \\
\text { about it. Other developers don't care; they } \\
\text { don't think it is relevant.' }\end{array}$ \\
\hline
\end{tabular}




\begin{tabular}{|l|l|l|}
\hline & $\begin{array}{l}\text { Homebuilder: } \\
\text { 'You may hear otherwise from other builders, } \\
\text { but I'll be honest with you, we have not } \\
\text { volunteered to change the way we do things } \\
\text { fundamentally and we are not looking to be } \\
\text { the innovators or leaders' } \\
\text { Architectural Consultant: } \\
\text { 'I see this as evil sometimes because we get } \\
\text { approval through design modifications, we } \\
\text { are doing standard gas bars or dealerships but } \\
\text { we are making them respond to more urban } \\
\text { pedestrian friendly orientations that actually } \\
\text { support public life itself...That sadly is what } \\
\text { my commissioned life has become' }\end{array}$ \\
\hline
\end{tabular}




\section{Notes}

${ }^{1}$ Field is here used following Bourdieu (2005) as a 'site of actions and reactions performed by social agents endowed with permanent dispositions, partly acquired in their experience of these social fields' (p. 30).

${ }^{2}$ Notable exceptions are Pryke and Du Gay (2002) in their culturalist account of how commercial property actors repaired markets following the 1990 crash, and Henneberry and Parris' (2013) argument for a project ecologies framework to analyse local property development networks. 